\title{
Obstetric acute kidney injury: A retrospective study
}

\author{
Alakananda, Anupama Hajong \\ Correspondence: Dr Alakananda, Professor, Department of Obstetrics and Gynaecology, \\ Gauhati Medical College, Guwahati, Assam; Email - dralakanandadas@gmail.com
}

Distributed under Creative Commons Attribution-Share Alike 4.0 International.

\begin{abstract}
Objective: To study the prevalence, aetiology and prognosis of obstetric acute renal failure (ARF). Methodology: This retrospective study was carried out in International Hospital, Guwahati from January 2002 to December 2009. Forty one (41) cases treated during this period was referred from various centres. Cases were analysed to find out the prevalence, causative factors and prognosis in relation to aetiology, time of referral, and severity of renal failure. Results: Out of 2022 admitted obstetrics patients 41 patients had ARF and were referred for PPH, sepsis, shock or oligo-anuria. Majority $(65.85 \%)$ patients were in the age group of 20 to 30years. Maximum cases $63.41 \%$ developed ARF during post partum period. Incidence was more following LSCS (46.34\%) compared to $17.07 \%$ following vaginal birth. Aetiology was found to be multifactorial and $76.47 \%$ patients recovered with haemodialysis. Mortality rate was (5/41) $12.20 \%$. Prognosis was found to be better in cases of early referral and worse in presence of sepsis. Conclusion: Obstetric ARF a problem of multifactorial aetiology, remains as an important cause of maternal death.
\end{abstract}

Keywords: Acute renal failure, pregnancy, sepsis, haemodialysis.

Obstetric ARF still remains as an important cause of maternal death. In developing countries incidence is around $4.2-15 \%$. Cases of APH, PPH, sepsis, dehydration, toxaemias of pregnancy and unsafe abortion are at risk of developing acute kidney injury (AKI) and usually it has multifactorial aetiology ${ }^{2}$. Unsafe abortion was one of the main cause of obstetric ARF worldwide and particularly in developing countries ${ }^{3}$. With legalisation of abortion there was marked decline of maternal death due to pregnancy related acute renal failure (PRARF). In spite of improvement in perinatal care, blood bank facilities, antibiotic prophylaxis, facilities for dialysis there are reports of maternal death even today due to obstetric
$\mathrm{ARF}$ and hence challenge remains in its prevention and related mortality and morbidity. This study was carried out to find out the prevalence, aetiological factor and prognosis of obstetric acute kidney injury.

\section{Materials and methods}

It is a retrospective hospital based study on Obstetrics ARF, carried out over a period of 7 years from January 2002 to December 2009 in International Hospital, Guwahati. Altogether 2022 numbers of obstetric patients were admitted and managed during the study period. Among them 41 cases were obstetric $\mathrm{ARF}$ and all were referred from various centres for $\mathrm{PPH}$, shock, sepsis or oligo-anuria.

Patients were selected on basis of the following

Received: $10^{\text {th }}$ April 2017. Accepted: $10^{\text {th }}$ June 2017.

Alakananda, Hajong A. Obstetric acute kidney injury: A retrospective study. The New Indian Journal of OBGYN. 2017; 4(1):54-8 
criteria: 1) Urine volume $<30 \mathrm{ml} / \mathrm{hr}$ for $6 \mathrm{hrs}$; or anuria, 2) Elevated creatinine level $>1.5 \mathrm{mg} / \mathrm{dl}$.

Detailed history and clinical findings were recorded. Investigations included complete blood count, liver function test, renal function test, coagulation profile, serum electrolyte, $\mathrm{C}$ reactive protein, malarial parasite test if febrile, USG whole abdomen, ECG, R/E and C/S urine. Decision for dialysis was taken depending on patient's clinical condition, creatinine level and presence of oligo-anuria. Patients were analysed according to age groups, parity, gestational status and mode of delivery. Cause of ARF was evaluated in each case. Prognosis was analysed in relation to aetiology, type of ARF, serum creatinine levels and time of referral to our hospital.

\section{Results and Observations}

During the 7 years of study period, out of 2022 obstetrics patients there were 41 referred cases of obstetric ARF. Incidence of pregnancy related acute renal failure (PRARF) was $2.02 \%$ out of all obstetric cases. Maximum cases $27(65.85 \%)$ was in the age group of 20-30 years. Out of 41 patients, $8(19.51 \%)$ were antenatal, $26(63.41 \%)$ were postnatal and $7(17.07 \%)$ were post abortal patients. Out of 8 antenatal cases 3 were in second trimester and 5 were in third trimester of pregnancy. Maximum cases ie.26 (63.41\%) developed ARF in postpartum period. Out of 26 postpartum cases 19 patients had undergone LSCS and 7 patients delivered vaginally. All of them were referred postpartum. Incidence of ARF was found to be more following CS (46.34\%) compared to vaginal delivery $(17.07 \%)$. ( $\mathrm{N}=\mathbf{4 1})$

\section{Table 1: showing aetiological break-up and its relation to prognosis}

\begin{tabular}{|c|c|c|c|c|c|c|c|c|}
\hline Cases & $\begin{array}{l}\text { Haemo } \\
\text { rrhage }\end{array}$ & $P I H$ & Anaemia & Sepsis & $A G E$ & $\begin{array}{l}\text { Malari } \\
a\end{array}$ & $U R D$ & $\begin{array}{l}P t . \\
\text { recovere } \\
d\end{array}$ \\
\hline Case 1 & + & + & & & & & + & + \\
\hline Case 2 & + & + & + & + & & & + & + \\
\hline Case 3 & + & + & + & & & & & + \\
\hline Case 4 & & + & + & + & & + & & + \\
\hline Case 5 & & + & & & & & & + \\
\hline Case 6 & & & + & + & & & & + \\
\hline Case 7 & & + & + & + & & & + & + \\
\hline Case 8 & & & & + & & & & + \\
\hline Case 9 & & & & + & & & + & + \\
\hline Case 10 & & + & + & + & & & + & + \\
\hline Case 11 & & & & & & & & + \\
\hline Case 12 & & & + & + & & + & + & + \\
\hline Case 13 & & + & + & + & & & + & + \\
\hline Case 14 & & & & + & & & + & DOR \\
\hline Case 15 & & & & + & & & + & + \\
\hline Case 16 & & & & + & & & & Expired \\
\hline Case 17 & + & & & + & & & & $D O R$ \\
\hline Case 18 & + & + & + & & & & & Expired \\
\hline Case 19 & & & + & + & & & & Expired \\
\hline Case 20 & + & + & & + & & & & Expired \\
\hline Case 21 & & + & & + & & & & + \\
\hline Case 22 & & & & & & + & & + \\
\hline Case 23 & & + & & & & & + & + \\
\hline Case 24 & & & + & + & & & + & + \\
\hline Case 25 & & & + & & & + & & + \\
\hline Case 26 & & & + & & & + & & + \\
\hline Case 27 & & & & + & & & + & + \\
\hline Case 28 & & & + & + & & & & Expired \\
\hline Case 29 & & & + & + & & & + & + \\
\hline Case 30 & & + & & + & & & & $D A M A$ \\
\hline Case 31 & & & + & + & + & & & DOR \\
\hline Case 32 & & & + & + & & & $+A D R F$ & $A D R F$ \\
\hline Case 33 & + & & + & & & & + & + \\
\hline Case 34 & & & + & + & & + & + & + \\
\hline Case 35 & & + & & + & & & + & + \\
\hline Case 36 & & & + & + & & & + & + \\
\hline Case 37 & & + & + & + & & & & + \\
\hline Case 38 & & + & + & + & & & & + \\
\hline Case 39 & & & + & + & + & & $O U$ & + \\
\hline Case 40 & & & + & + & & & & $D O R$ \\
\hline Case 41 & & & & + & & & + & + \\
\hline Total & 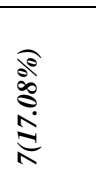 & 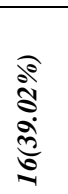 & 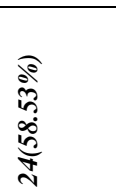 & $\begin{array}{l}\frac{2}{6} \\
\frac{n}{2}\end{array}$ & 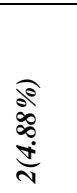 & $\begin{array}{l}\frac{0}{8} \\
\frac{8}{5} \\
\frac{ \pm}{6}\end{array}$ & 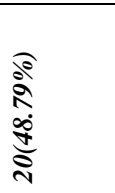 & $\frac{\sqrt{2}}{\sqrt{2}}$ \\
\hline
\end{tabular}

DOR $=$ Discharge on request, DAMA $=$ Discharge against medical advice, $D O R=$ Discharge on request, $D A M A=$ Discharge
$U R D=$ Underlying renal disease, $O U=$ Obstructive Uropathy

Analysing the causes of AKI it has been found to be multifactorial in each case as shown in the table 1 . Sepsis was found to be the most common causative factor of obstetric ARF existing in $75.61 \%$ cases followed by anaemia $58.53 \%$, underlying renal disease 
Table 2: Showing prognosis in relation to dialysis and creatinine level

\begin{tabular}{|c|c|c|c|c|c|c|}
\hline \multirow{2}{*}{$\begin{array}{l}\text { Creatinine range } \\
\text { in }(\mathbf{m g} / \mathbf{d l}) \\
\mathrm{N}=\text { patients }\end{array}$} & \multicolumn{3}{|c|}{ No of patients dialysed, $N=35$} & \multirow{2}{*}{$\begin{array}{l}\text { Recovered } \\
\text { without } \\
\text { dialysis } \\
\mathbf{N}=\mathbf{3}\end{array}$} & \multirow{2}{*}{$\begin{array}{l}\text { Dialysis } \\
\text { could not } \\
\text { be done } \\
\mathrm{N}=3\end{array}$} & \multirow{2}{*}{$\begin{array}{l}\text { Total patients } \\
\text { recovered } \\
\mathrm{N}=30\end{array}$} \\
\hline & $\begin{array}{l}\text { Recove } \\
\text { - red } \\
\mathrm{N}=27\end{array}$ & $\begin{array}{l}\text { Not } \\
\text { recovered } \\
\mathrm{N}=4\end{array}$ & $\begin{array}{l}\text { Treatment not } \\
\text { continued, } \\
\mathrm{N}=4\end{array}$ & & & \\
\hline$>0.9$ to $<5(\mathrm{~N}=13)$ & 7 & 1Expired (E) & $\begin{array}{l}1 \text { Discharge on } \\
\text { request (DOR) }\end{array}$ & 2 & 1E,1DOR & $9 / 13(69.2 \%)$ \\
\hline$>5$ to $<10(\mathrm{~N}$ & 17 & $1 \mathrm{E}, 1 \mathrm{ADRF}$ & 3DOR & 1 & & $18 / 23(78.3 \%)$ \\
\hline$>10(\mathrm{~N}=5)$ & 3 & $1 \mathrm{E}$ & & & $1 \mathrm{E}$ & $3 / 5(60 \%)$ \\
\hline
\end{tabular}

48.79\%, PIH $39.02 \%$, haemorrhage $17.08 \%$, malaria $14.63 \%$ and acute gastroenteritis $4.88 \%$.

There were eight antenatal cases including three in second trimester and five in third trimester of pregnancy. Six (75\%) of them recovered, one (12.5\%) expired, one discontinued treatment. There were three IUD, one abortion leading to $50 \%$ adverse fetal outcome and pregnancy continued in four of them.

Prognosis was worst among patients having sepsis as $22(70.96 \%)$ patients with sepsis, $18(75 \%)$ patients with anaemia and $13(81 \%)$ patients with $\mathrm{PIH}$ recovered. Among the 5 cases that expired, 4 (80\%) cases had sepsis. Sepsis found to be most common causative factor and a poor prognostic factor for obstetric AKI. Prognosis was not found to be related to pregnancy status as mortality was similar $12.5 \%$ ( 1 out of 8 ) in antenatal cases and $12.1 \%$ (4 out of 33 ) in postpartum cases. Out of 41, maximum nos 38 (92.6\%) cases had oliguric renal failure and only 3 cases presented with nonoliguric AKI.

Fourteen

(14) patients presented in emergency within $48 \mathrm{hrs}$ of detection of ARF whereas 27 of them presented after 48 hrs. Among patients referred within $48 \mathrm{hrs}$ there was no mortality and recovery was more $(85.71 \%)$ compared to those reporting after $48 \mathrm{hrs}$ $(66.66 \%)$.

Cases were divided into 3 groups according to creatinine level: Group A $>0.9$ - $<5$, Group B $>5$ $<10$, and Group $\mathrm{C}>10$ with 13, 23, and 5 cases respectively. Maximum cases were found in group B. Recovery in relation to creatinine level were $69.2 \%$ (9/13), 78.3\%(18/23), 60\%(3/5) in group A,B,C respectively having maximum recovery in group $\mathrm{B}(>5$ - <10 creatinine). Hence recovery was not found to be related to severity of renal failure.

Out of 41 cases 31 cases completed treatment, 4 discontinued treatment, 3 recovered without dialysis and dialysis could not be done in 3. Among dialysed cases $87.09 \%(27 / 31)$ fully recovered and mortality was $9.6 \%(3 / 31)$ but mortality was $66.6 \%(2 / 3)$ in whom dialysis could not be done because of poor clinical condition due to late referral.

\section{Discussion}

Table 3: Incidence of PRARF by different authors

\begin{tabular}{lllllll}
\hline Authors & Period & $\begin{array}{l}\text { PRA } \\
\text { - RF }\end{array}$ & $\begin{array}{l}\text { Total } \\
\text { AKI }\end{array}$ & $\begin{array}{l}\text { Obstetr } \\
\text {-ic cases }\end{array}$ & $\begin{array}{l}\text { PRARF } \\
\text { /ARF }\end{array}$ & $\begin{array}{l}\text { PRARF/total } \\
\text { preg. Cases }\end{array}$ \\
\hline Rubina et al $^{4}$ & Jan1990-dec2014 & 1441 & & & $25.62 \%$ & \\
Lutfullah et al $^{5}$ & 1997-2001 & 36 & 283 & & $12.7 \%$ & \\
Kilari et al $^{3}$ & Jul 1999-dec 2004 & 41 & 966 & & $4.24 \%$ & \\
Goplani et al $^{6}$ & 2006 & 70 & 772 & & $9.06 \%$ & \\
Ansari et al $^{7}$ & Nov 2004-oct 2005 & 42 & 116 & & $36 \%$ & \\
Irfana et al $^{8}$ & Aug 2007-july2008 & 43 & 130 & & $33.76 \%$ & \\
Rizwan et al $^{9}$ & Oct 2009-sep 2010 & 35 & & 3285 & & $1.065 \%$ \\
Arrayhani et al $^{10}$ & Feb 2011-jan 2012 & 37 & & 5600 & & $0.66 \%$ \\
Present study & Jan 2002-dec2009 & 41 & 2062 & 2022 & $1.98 \%$ & $2.03 \%$ \\
\hline
\end{tabular}


Incidence of PRARF was found to be $2.03 \%$ of total obstetric patients and $1.98 \%$ of total ARF patients. Wide variation of incidence observed in different studies may be related to lack of uniformity in health

Table 4. Showing declining incidence in Indian scenario

\begin{tabular}{llll}
\hline Author & Year & $\begin{array}{l}\text { Total } \\
\text { PRARF }\end{array}$ & $\begin{array}{l}\text { PRARF/ } \\
\text { ARF }\end{array}$ \\
\hline${\text { Chug et } \mathrm{al}^{2}}^{2}$ & 1987 & 46 & $14.5 \%$ \\
Prakash et al $^{1}$ & 1995 & 59 & $13.9 \%$ \\
Rani et al $^{11}$ & 2002 & 82 & $12.2 \%$ \\
Kilari et al $^{3}$ & 2005 & 41 & $4.3 \%$ \\
Goplani et al $^{6}$ & 2008 & 70 & $9.06 \%$ \\
Present study & & 41 & $1.98 \%$ \\
\hline
\end{tabular}

care delivery system (table 3 ). In the Indian scenario incidence is declining from 1987 (table 4). The present study findings indicate improvement of health care delivery system. Maximum number of patients

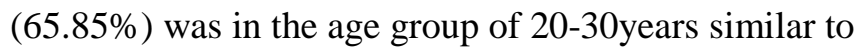

Table 5: PRARF in relation to gestational status in different studies

\begin{tabular}{llll}
\hline Study & Antenatal & Puerperium & Postabortal \\
\hline Kilari et al $^{3}$ & $17.07 \%$ & $75.61 \%$ & $9.76 \%$ \\
Irfana et al $^{8}$ & $16.3 \%$ & $83.7 \%$ & \\
Goplani et al $^{6}$ & $7.14 \%$ & $72.85 \%$ & $20 \%$ \\
$\begin{array}{l}\text { Arrayhani et } \\
\text { al }\end{array}$ & $61.1 \%$ & $22.2 \%$ & $18.9 \%$ \\
$\begin{array}{l}\text { Lutfullah et al } \\
\text { Present study }\end{array}$ & & & \\
\hline
\end{tabular}

reported by Arrayhani et al ${ }^{10}$ i.e. $73 \%$ at $22 \mathrm{yrs}$. Mean age of patients reported by Kilari et $\mathrm{al}^{3} 26.2$ years, Irfana Hassan et $\mathrm{al}^{8}$ as $25+/-6.1$ year, Goplani et $\mathrm{al}^{6}$ 25.6 years and Mohammad Ansari et $\mathrm{al}^{7}$ 28years, Lutfullah et $\mathrm{al}^{5} 30-40$ yrs (61.1\%), Rizwan et $\mathrm{al}^{9} 30$ $35 y$ rs.

Etiology was found to be multifactorial including sepsis in $75.61 \%$, anemia in $58.53 \%$, PIH in $39.02 \%$, hemorrhage in $17.07 \%$ cases. Similarly Kilari et $\mathrm{al}^{3}$ observed puerperal sepsis as the most common cause of PRARF including $19.51 \%$ following CS, $9.76 \%$ following vaginal delivery and septic abortion each.
Utas et al ${ }^{12}$ reported eclampsia 50\%, HELLP syndrome $15.7 \%$, PPH $14.3 \%$, septic abortion in $11.4 \%$ cases. Selcuk et al ${ }^{13}$ found abortion in $30 \%$ and PPH in $15 \%$ cases of PRARF. Rizwan et $\mathrm{al}^{9}$ reported PPH $31.42 \%$, APH $25.71 \%$, eclampsia $17.14 \%$, DIC $14.28 \%$ and sepsis in $11.42 \%$ of PRARF. Arrayhani et $\mathrm{al}^{10}$ observed hypertension in $55.6 \%$ cases. Sepsis, hemorrhage and $\mathrm{PIH}$ are found to be common causative factors in all the studies. According to Lutfullah et $\mathrm{al}^{5}$ HELLP syndrome was the most common cause of PRARF $44 \%$.

Maximum cases $92.68 \%$ had oligo-anuria similar to the observation by Irfana et $\mathrm{al}^{8}(18.6 \%$ anuric, $76.7 \%$ oliguric), Goplani et $\mathrm{al}^{6}(35.71 \%$ anuric, $62.85 \%$ oliguric), Lutfullah et $\mathrm{al}^{5}$ (100\% oliguric), Ansari et $\mathrm{al}^{7}$ (45\% anuric,55\% oliguric) and Rubina et $\mathrm{al}^{4}(42.84 \%$ anuric, $50.88 \%$ oliguric). Non-oliguric AKI was $7.31 \%$ which was more than reported by Irfana et $\mathrm{al}^{8} 4.6 \%$ and Goplani et $\mathrm{al}^{6} 1.4 \%$.

As shown in the table 5, in most of the studies maximum patients developed AKI in the postpartum period except Arrayhani et al ${ }^{10}$ who observed more in antenatal cases. We observed more cases of AKI following LSCS compared to vaginal delivery and this observation was not similar to other studies which may be due to multifactorial aeiology of PRAKI and variation in the incidence of $C S$ in different centres due to different protocol (table 6). Out of 8 antenatal cases $75 \%$ recovered, $12.5 \%$ maternal death but fetal loss was $50 \%$. No such parameters obtained from other studies for comparision. Prognosis was worst among patients having sepsis as 4 out of 5 deaths $(80 \%)$ had sepsis. Patients referred within 48 hrs there was no

Table 6: Mode of delivery of postpartum cases

\begin{tabular}{lll}
\hline Study & $\begin{array}{l}\text { LSCS } \\
\text { \% }\end{array}$ & $\begin{array}{l}\text { Vaginal } \\
\text { \% }\end{array}$ \\
\hline${\text { Kilari et } \mathrm{al}^{3}}^{3}$ & 36.59 & 36.59 \\
& & \\
${\text { Ansari et } \mathrm{al}^{7}}^{7}$ & 29 & 71 \\
Lutfullah et al $^{5}$ & 48 & \\
Arrayhani et $^{10}$ & 40.5 & 40.5 \\
Present study & 46.34 & 17.07 \\
\hline
\end{tabular}


mortality and recovery was rapid $(85.71 \%)$ compared to those reporting after $48 \mathrm{hrs}(66.66 \%)$. Recovery was not found to be related to creatinine level as maximum recovery observed $(78.3 \%)$ in serum creatinine group $>5-<10$ where as it was $69.2 \%$ in $>0.9-<5$ creatinine group and $60 \%$ in $>10$ creatinine group. Patients who completed treatment had $87.09 \%$ recovery and $9.6 \%$ mortality where as mortality was $66.6 \%$ in patients in whom dialysis could not be done due to poor clinical condition resulting from late referral. Maternal mortality was found to be $12.20 \%$ which is less than reported by Chug et $\mathrm{al}^{2}$ (1987) 30\%, Kilari et $\mathrm{al}^{3}$ (2005) $24.39 \%$, Goplani et $\mathrm{al}^{6} 18.57 \%$, Irfana et $\mathrm{al}^{8} 16.2 \%$. Declining incidence indicates improvement in health care delivery system.

\section{Conclusion}

Obstetric AKI still remains as an important cause of maternal death and pregnancy loss. It is usually multifactorial and sepsis being the most common cause in our population. Volume depletion, sepsis, anaemia, hypertensive disorders and underlying renal disease are the risk factors. Mostly develops in the postpartum period and more following CS. It is preventable by identifying cases at risk, prompt volume replacement, control of sepsis avoiding nephrotoxic drug, correction of anaemia and control of hypertension. Challenge still remains in its prevention which is possible by anticipation and awareness being vigilant in high risk cases. Mortality and morbidity can be prevented by early detection and initiation of treatment at the earliest.

\section{Conflict of interest: None. Disclaimer: Nil. References}

1.Prakash J, Kumar H, Sinha DK, Kedalya PG, Pandey LK, Srivastava PK, et al. Acute renal failure in pregnancy in a developing country: 20 years of experience. Ren Fail. 2006; 28: 309-13.

2.Chugh KS, Sakhuja V, Malhotra HS, Pereira BJ. Changing trend in acute renal failure in third-world countries: Chandigarh study. Quart J Med. 1989; 73(272):1117-23.3.Kilari SK, Chinta RK, Vishnubhotla SK. Pregnancy related acute renal failure. J Obstet Gynecol India.2006; 56: 308-10.
4.Naqvi R, Akhtar F, Ahmed E, Naqvi A, Rizvi A. Acute Kidney Injury with Rhabdomyolysis: 25 Years Experience from a Tertiary Care Center. Open Journal of Nephrology. 2015; 5: 67-74.

5.Lutfullah A, Kazim G, H. Zeki T, Cetin C, Ibrahim G. Etiology and prognosis in 36 acute renal failure cases related to pregnancy in central Anatolia. Europian Journal of Genaral Medicine. 2005; 2(3): 110-13.

6.Goplani KR, Shah PR, Gera DN, Gumber M, Dabhi M, Feroz A. Pregnancy - related acute renal failure: A single center experience. Indian Journal of Nephrology. 2008; 18(1):17-21.

7.Ansari MR, Laghari MS, Solangi KB. Acute renal failure in pregnancy: one year observational study at Liaquat University Hospital, Hyderabad. J Pak Med Assoc. 2008; 58: 61-4.

8.Hassan I, Junejo AM, Dawani ML, et al. Etiology and Outcome of Acute Renal Failure in Pregnancy. Journal of the College of Physicians and Surgeons Pakistan. 2009; 19 (11): 714-17.

9.Rizwan N, Uddin SF. Obstetrical acute renal failure: a challenging medical complication. J Ayub Med Coll Abbottabad. 2011; 23 (4): 66-8

10.Arrayhani M, El Youbi R, Sqalli T. Pregnancy-related acute kidney injury: Experience of the nephrology unit at the university hospital of fez, morocco. ISRN Nephrol. 2013:109034

11.Rani PU, Narayen G. Changing trends in pregnancy related acute renal failure. J Obstet Gynecol India. 2002; 8: 36-8.

12.Utas C, Yalcindag C, Taskapan H, Guven M, Oymak $\mathrm{O}$, Yuceosy M. Acute renal failure in Central Anatolia. Nephrol Dial Transplant. 2000; 15:152-5.

13.Selcuk NY, Odabas AR, Cetenkaya R, Tonbol HZ, San A. Outcome of pregnancies with HELLP syndrome complicated by acute renal failure (1989-1999). Ren Fail. 2000; 22: 319-27.

\footnotetext{
Alakananda ${ }^{1}$, Anupama Hajong ${ }^{2}$

${ }^{1}$ Professor, Department of Obstetrics and Gynaecology, Gauhati Medical College, Guwahati, Assam, India; ${ }^{2}$ Gynaecologist, International Hospital, Guwahati, Assam, India.
} 